\title{
Experimental translocations of the threatened New Zealand plants Carex inopinata Cook (Cyperaceae) and Simplicia laxa Kirk (Poaceae)
}

\author{
Kelvin Lloyd ${ }^{1}$, Valerie Fay ${ }^{2}$ and Luke Easton ${ }^{3 *}$ \\ ${ }^{1}$ Wildland Consultants Ltd, 764 Cumberland Street, Dunedin 9016, New Zealand \\ ${ }^{2} 827$ Mt Cargill Road, Waitati 9085, New Zealand \\ ${ }^{3}$ Department of Zoology, University of Otago, PO Box 56, Dunedin 9054, New Zealand \\ *Author for correspondence (Email: lukeeaston@outlook.com)
}

Published online: 24 May 2018

\begin{abstract}
Carex inopinata Cook (Cyperaceae) and Simplicia laxa Kirk (Poaceae) are two threatened 'grassy' plants that generally occur in dry grassland and rock outcrop habitats. However, the restriction of these species to such areas may indicate relict habitats. We tested this idea by translocating both species to Ōrokonui Ecosanctuary, near Dunedin. Carex inopinata was translocated to two sites (moderately- and highly-shaded) in 2010 and Simplicia laxa was translocated in 2011, but only to one site due to insufficient propagated material. At each site, plants were established in different microhabitats underneath a kānuka (Kunzea robusta) canopy, where ground cover was sparse and hence provided minimal competition for the translocated plants. We measured plant growth, flowering, and survival twice-yearly from 2010 to 2013, and again from 2015 to 2017. Also, we described the vegetation and recorded microclimate data at each site. Carex inopinata growth, flowering, and survival were highest under moderate shade, either in open (bare-ground) or beside-rock microhabitats. Highest growth levels alternated between these two microhabitats, particularly during a drought when plants in the open suffered some mortality or damage, while plants near rocks remained sheltered. Narrower ranges of relative humidity and temperature in rock versus open microhabitats attest to probable protection from drought. Despite $42 \%$ of originally planted $C$. inopinata individuals surviving, there was no seedling recruitment, therefore, the long-term persistence of this translocated population remains uncertain. Simplicia laxa did not successfully establish, although growth was also highest in open microhabitat. We cannot confirm whether habitat for $S$. laxa at Ōrokonui is absent but drought-related mortality influenced its failure to establish. Further monitoring of the $C$. inopinata plants will confirm whether this threatened sedge can persist under the conditions present at the translocation site.
\end{abstract}

Key words: Cyperaceae; Ōrokonui Ecosanctuary; plants; Poaceae; translocations

\section{Introduction}

Translocations of threatened plants are commonly performed to mitigate adverse effects on threatened plant populations through augmentation or the establishment of new ones (Monks 2008; Godefroid et al. 2011). While biological success (i.e. the establishment of viable self-sustaining populations) is the primary aim of translocations, 'project success' should also be considered, such as lessons learned from the translocation process (Monks 2008). In other words, project success is the refinement of translocation techniques, which are of course shaped by biological successes and failures. Experimental translocations of plants are an important component of enhancing biological and project success. As such, subsequent translocations of threatened plants may achieve biological success more cost-effectively (Monks 2008). However, the optimisation of translocation success is largely governed by three potential limitations: (1) the threatened status of the target species, as there may be insufficient individuals to expend in replicated trials of highly threatened taxa; (2) the availability of long-term monitoring data to verify the prospects of success; and (3) the ability to communicate findings and access or share data (Armstrong \& Seddon 2008; Monks 2008; Godefroid et al. 2011; Easton 2015). Moreover, there is often uncertainty regarding the habitat requirements of target species given that current distributions may not reflect optimal habitat (i.e. habitat that support viable populations)
(Osborne \& Seddon 2012). Therefore, it may be difficult to discern the effect of management actions on populations over time if habitat quality is low or required habitat is absent. For example, in Western Australia, an experimental translocation of the critically endangered Banksia ionthocarpa subsp. ionthocarpa (Proteaceae) seedlings with and without shade cloth revealed no differences in survival, height, and growth between the two groups as both populations declined and only about $6 \%$ of seedlings survived after 8 years (Monks 2008). Fortunately, there are circumstances where experimental translocations can be useful in addressing uncertainties regarding habitat requirements (Jusaitis 2005). Therefore, experimental translocations comprise two main types: those where plants are translocated to similar habitat conditions but with different horticultural techniques (e.g. shade cloth versus no shade cloth) and those where plants are translocated to multiple microhabitats that experience different environmental conditions. For the latter, variation in plant growth and survival indicate habitat requirements and the quality of those resources (i.e. an ability to provide conditions necessary for individual reproduction and survival, thereby persistence of the population) (Mathewson \& Morrison 2015). Population demographics fluctuate spatially and temporally; so too does habitat quality (Mathewson \& Morrison 2015), which is why long-term monitoring of populations is important to capture such patterns. 
In New Zealand, determining habitat requirements and quality of threatened plants are key conservation priorities (e.g. Jones 2004). We addressed this conservation objective for two species endemic to the South Island, Carex inopinata Cook (Cyperaceae) and Simplicia laxa Kirk (Poaceae), by studying their experimental translocation to a fenced mainland sanctuary, Ōrokonui Ecosanctuary (Dunedin, South Island), from which pest mammals were eradicated in 2008. Re-incursions of pest mammals (e.g. mice, Mus musculus) occasionally occur but management responses are rapid and either eliminate or reduce pests to undetectable levels as determined by intensive and extensive monitoring. As a protected site under conservation management, one of the reasons for choosing the Ecosanctuary is that should either of these plant species persist, then the longterm future of the population would be more assured. Carex inopinata and S. laxa are considered Nationally Vulnerable and Nationally Critical, respectively, under the New Zealand Threat Classification System (de Lange et al. 2013). Both species are low-growing and rather difficult to identify, especially when not in fruit (Morgan \& Norton 1992; Jones 2004; Ogle 2010). These species apparently share a similar niche as they both grow in well-drained and fertile substrates that are either base-rich, alluvial, limestone, or schist (Jones 2004). Although little is known about their historical distribution, records have revealed local extirpation of $C$. inopinata at $\mathrm{Mt}$ Koinga (Central Otago), and S. laxa has apparently become extinct from several locations near Dunedin (Kirk 1987; Jones 2004; Smissen et al. 2011). Currently, C. inopinata is restricted to fragmented or single populations in the Southland, Otago, Canterbury, and South Marlborough regions (Molloy 1991; Jones 2004), whereas S. laxa is restricted to Otago and Nelson regions (Ogle 2010; Smissen et al. 2011; de Lange et al. 2014, 2016). Carex inopinata and $S$. laxa generally grow in dry grassland and rock bluff and tor habitats (Jones 2004; Ogle 2010; Smissen et al. 2011; de Lange et al. 2014, 2016). Whether the current distribution of these species reflects relict or optimal habitats is unknown (Jones 2004).

Identifying habitat requirements and establishing new wild populations as security against further local extirpation, or even extinction, are two main objectives to facilitate the longterm management of these species (Dopson et al. 1999; Jones 2004). Based on experimental observations of $C$. inopinata growth under different light regimes, Morgan and Norton (1992) concluded that the primary habitat requirement for $C$. inopinata is open forest or shrubland. Field observations of North Island Simplicia taxa have suggested a similar conclusion for Simplicia laxa habitat (Ogle 2010; Smissen et al. 2011; de Lange et al. 2014, 2016). For this reason, we hypothesised that microhabitats such as rock overhangs and highly-shaded sites are relict refuges from factors that promote habitat loss (e.g. grazing and fire), rather than optimal habitats. Our study investigates the potential for various microhabitats to support growth, survival and recruitment of the two focal species and thus builds on earlier observational studies to contribute proactively to their conservation (Morgan \& Norton 1992; Ogle 2010; de Lange et al. 2014).

\section{Materials and methods}

\section{Translocation}

Mature plants were originally collected from the wild by M. Thorsen (Department of Conservation). One individual
C. inopinata was sourced from Rock and Pillar Creek $\left(45^{\circ} 22^{\prime} 01.34^{\prime \prime} \mathrm{S}, 170^{\circ} 00^{\prime} 13.8^{\prime \prime} \mathrm{E}\right)$, and three individuals were sourced from Alexandra, Central Otago $\left(45^{\circ} 15^{\prime} 57.01^{\prime \prime}\right.$ S, $169^{\circ} 22^{\prime} 48.28^{\prime \prime}$ E). Simplicia laxa were obtained from various populations at Macraes Flat, Otago (4527'36.53" S, $\left.170^{\circ} 25^{\prime} 21.01 \mathrm{E}^{\prime \prime}\right)$. We divided and propagated plants for each species in a shade-house to generate sufficient individuals for replication across different microhabitats and sites. Due to differences in the timing at which plants from different sites were obtained, the initial size of propagated individuals of $C$. inopinata differed between the two collection sites; the Alexandra plants were smaller than those sourced from Rock and Pillar Creek at planting in 2010. Simplicia laxa was propagated during 2010 and planted in 2011. Initial sizes of individual $S$. laxa were all similar.

We selected two destination sites (Table 1) in Ōrokonui Ecosanctuary, a 307 ha reserve approximately $20 \mathrm{~km}$ north of Dunedin. Relatively dry, open, kānuka (Kunzea robusta) forest was chosen to reduce above-ground competition for the planted species. Site $1\left(45^{\circ} 46^{\prime} 33.27^{\prime \prime} \mathrm{S}, 170^{\circ} 36^{\prime} 01.07^{\prime \prime}\right.$ E) was a moderately-shaded, apparently warmer site on a gentle north-facing slope with scattered small volcanic rock outcrops. Site $2\left(45^{\circ} 46^{\prime} 36.48^{\prime \prime} \mathrm{S}, 170^{\circ} 35^{\prime} 58.57^{\prime \prime} \mathrm{E}\right)$ was a more shaded and apparently cooler, steeper, west-facing slope, dominated by large volcanic rock outcrops. We translocated 74 individuals of $C$. inopinata in total across both sites. Each founder population comprised individuals sourced from the two provenances: Site 1 had 24 plants sourced from Rock and Pillar Creek and 16 from Alexandra, while Site 2 had 22 plants sourced from Rock and Pillar Creek and 12 from Alexandra. Carex inopinata were planted within several different microhabitats: (1) beneath rock overhangs (Site 1: $\mathrm{n}=3$; Site $2: \mathrm{n}=28$ ), (2) beside (directly adjacent to) rocks but not under overhangs (Site 1: $n=17$; Site 2: $n=6$ ), and (3) in the open at least $1 \mathrm{~m}$ away from rocks (Site 1 only: $\mathrm{n}=$ 20). Rock overhangs were limited in Site 1 and there were no open (bare-ground) microhabitats at Site 2, so only the first two microhabitats were planted. Individuals were randomly allocated to sites and microhabitats, such that plants from the different provenances were replicated over most site/ microhabitat combinations. Planting occurred in May 2010, and we undertook the first measurements two weeks later. In 2011 , there were only 36 S. laxa plants available for planting, as this species was obtained at a later stage and grew more slowly in cultivation, therefore, only Site 1 was used. We planted $S$. laxa in each of the three microhabitats (rock overhang: $\mathrm{n}=$ 6; beside-rock: $\mathrm{n}=18$; open: $\mathrm{n}=12$ ) at Site 1 in May 2011, adjacent to, but not within, the area where $C$. inopinata was planted. Like $C$. inopinata, we initially measured $S$. laxa plants two weeks after planting. We measured $C$. inopinata twice-yearly in May and November from 2010 to 2013, and we measured $S$. laxa at the same times from 2011 to 2013. Additional measurements were undertaken of all surviving plants at both sites in November 2015, twice in 2016, and in 2017. For each plant, we counted the number of shoots present and we used a ruler to measure the orthogonal length and width (i.e. shoot extent) of naturally hanging leaves. If flowering shoots were present, they were counted.

A single $10 \mathrm{~m} \times 10 \mathrm{~m}$ vegetation plot was established in a representative area in each site to provide quantitative information on vegetation structure and composition (Table 1). All vascular plant species that occurred in each plot were identified and recorded. Trees and shrubs shorter than $2 \mathrm{~m}$ tall were counted in three height classes, and those taller 
Table 1: Summary of topography and vegetation at the two translocation sites within Ōrokonui Ecosanctuary.

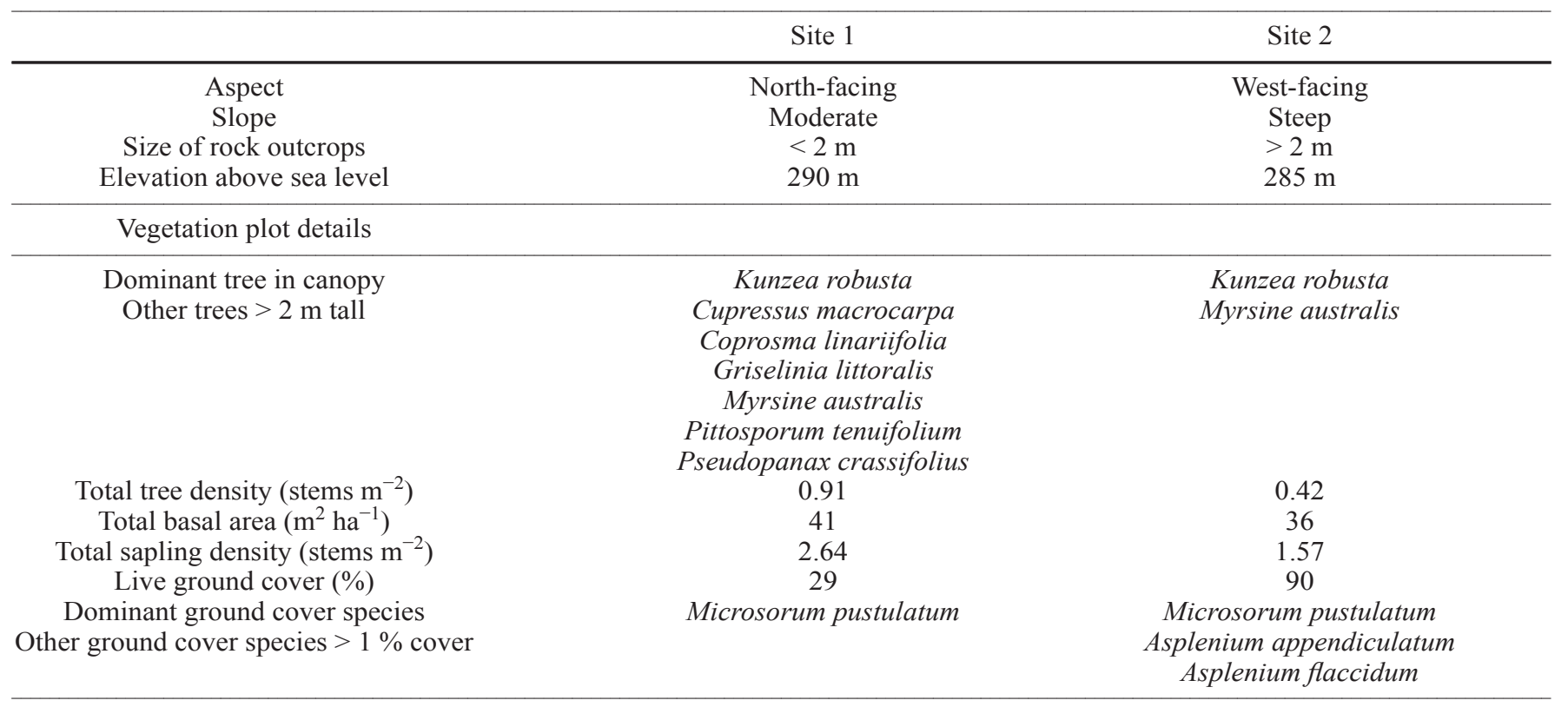

than $2 \mathrm{~m}$ had their stem diameters measured at breast height $(1.3 \mathrm{~m})$. All tree and shrub individuals within each plot were either counted or measured. In addition, in the austral winter of 2017 , a $0.25 \mathrm{~m}^{2}$ quadrat was centred on each surviving or dead plant in order to estimate ground cover within the quadrat in three categories: vascular plant cover $(\leq 30 \mathrm{~cm}$ tall, excluding $C$. inopinata cover), rock cover, and cover of litter, soil, and bryophytes.

In the austral summer of $2016 / 17$, three iButton (DS1922L/T, Maxim Integrated) temperature and humidity logging devices were deployed across the small elevation range in each site. At Site 1, the iButtons were established in open, beside-rock and rock overhang microhabitats, whilst at Site 2 , the iButtons were placed under rock overhangs. The iButtons recorded air temperature $\left({ }^{\circ} \mathrm{C}\right)$ and relative humidity (\%) every hour, from 20 December 2016 to 3 March 2017. One iButton failed at Site 2 (mid-slope elevation), leaving data from five devices available for analysis.

\section{Statistical analyses}

To determine the influence of microhabitat and site on shoot extent for C. inopinata over time (2011-2016), we used a repeated measures, linear mixed-effects model ('lme4' $\mathrm{R}$ package version 1.1-5; Bates et al. 2014) with shoot extent as the response, and microhabitat and site as predictor variables. We included initial plant size and provenance source (i.e. source location) as covariates to account for other sources of variation that might influence plant growth. The predictor variables microhabitat and site were interacted with time. We treated plant identity as a random factor to account for between and within-individual variation. Likewise, we determined site and microhabitat effects on $C$. inopinata flowering using the same parameters except with the number of inflorescences as the response and by using a generalised mixed-effects negative binomial model ('glmmADMB' R package version 0.8.0; Fournier et al. 2012; Skaug et al. 2014). To assess the influence of microhabitat on $S$. laxa shoot extent, site and plant size were excluded as predictor variables in a linear mixed effects model, but provenance was retained (for $S$. laxa provenance refers to source population and, for one group, germination from seed). The interaction between time and microhabitat was also excluded on the basis that power was severely reduced when this parameter was included within the model. Shoot extent and flowering data were log-transformed as required to meet assumptions of normality. Survival of $C$. inopinata and $S$. laxa were modelled using a Cox proportional hazard model ('survival' R package version 2.37-7; Therneau $\&$ Grambsch 2000). The same predictor variables were used for each plant species as before, except that vascular plant cover was included as an additional variable for $C$. inopinata survival. Model diagnostics for all models were checked and the assumptions of normality and constant variance were met. Model estimates are reported as coefficient estimates $\pm 2 \mathrm{SE}$ and were considered significant if the confidence intervals did not contain zero. All analyses were performed in $\mathrm{R}$ version 3.0.2 (R Core Team 2013).

\section{Results}

\section{Microclimate}

Average air temperature was similar across sites and microhabitats but the range of temperatures was slightly lower under rock overhangs than in open or beside-rock microhabitats (i.e. overhangs were more sheltered) (Fig. 1). The same pattern was observed for relative humidity (Fig. 1). At Site 2, the rock overhang at low elevation (i.e. down-slope) was more sheltered than the rock overhang at the highest elevation (i.e. up-slope) (Fig. 1).

\section{Carex inopinata}

Average shoot extent of $C$. inopinata initially decreased during the first year due to post-translocation mortality. Since then, growth of most plants recovered and survivorship remained stable for several years before an El Niño drought in 2015 (January total rainfall in Dunedin was 68\% less than normal; NIWA 2017). There were observed differences in survival and 


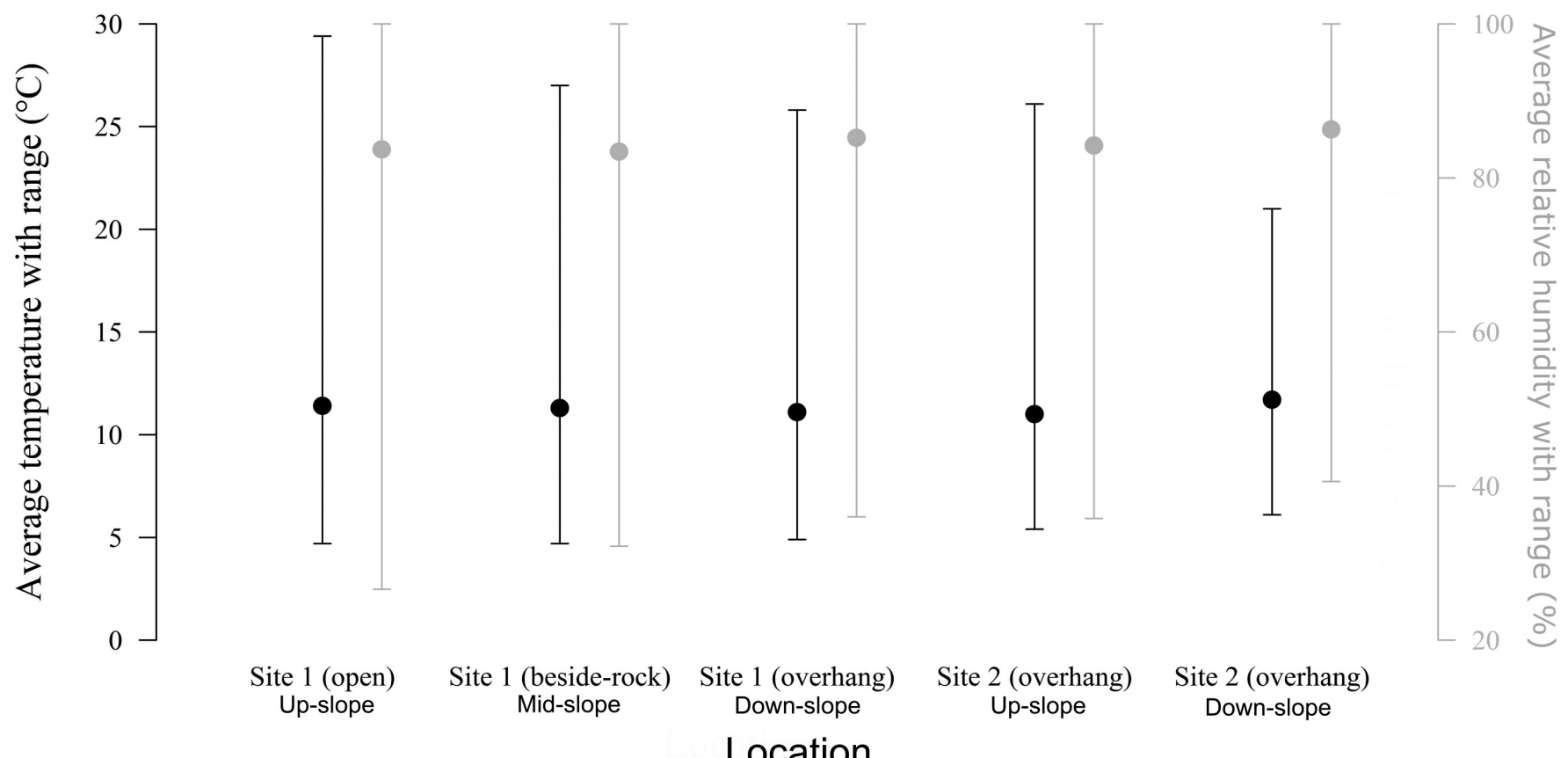

Figure 1: Average, minimum and maximum air temperature $\left({ }^{\circ} \mathrm{C}\right)$ (black), and relative humidity $(\%)$ (grey), recorded from December 2016 to March 2017 across the elevation range at Sites 1 and 2 within the assessed microhabitats. One iButton failed at Site 2 (mid-slope) thus data were not collected from this location.

A.

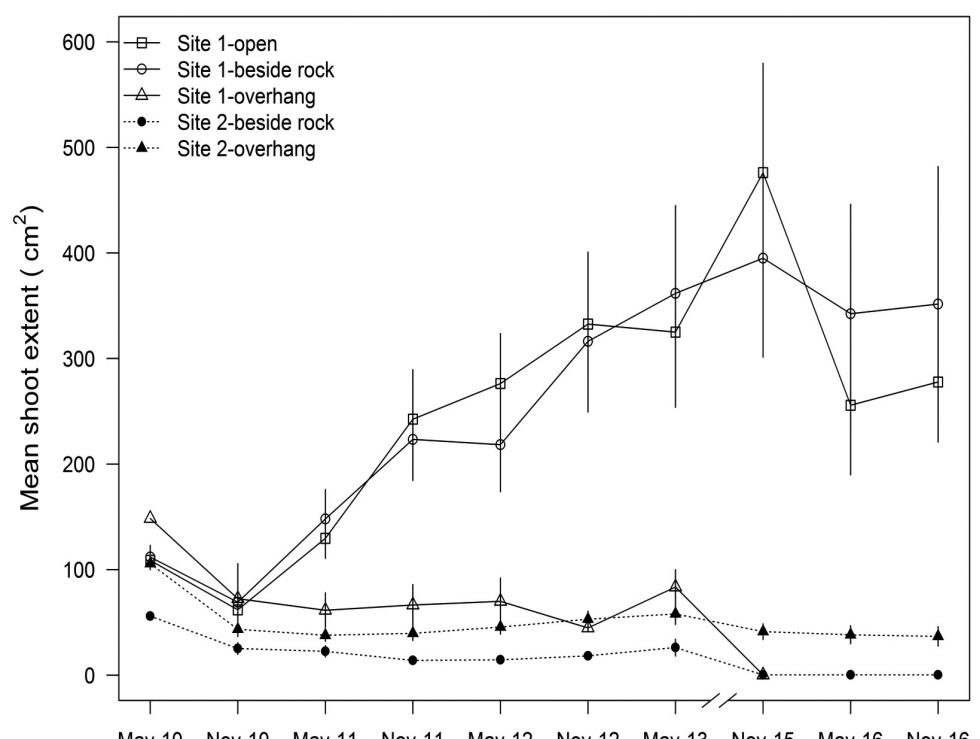

B.

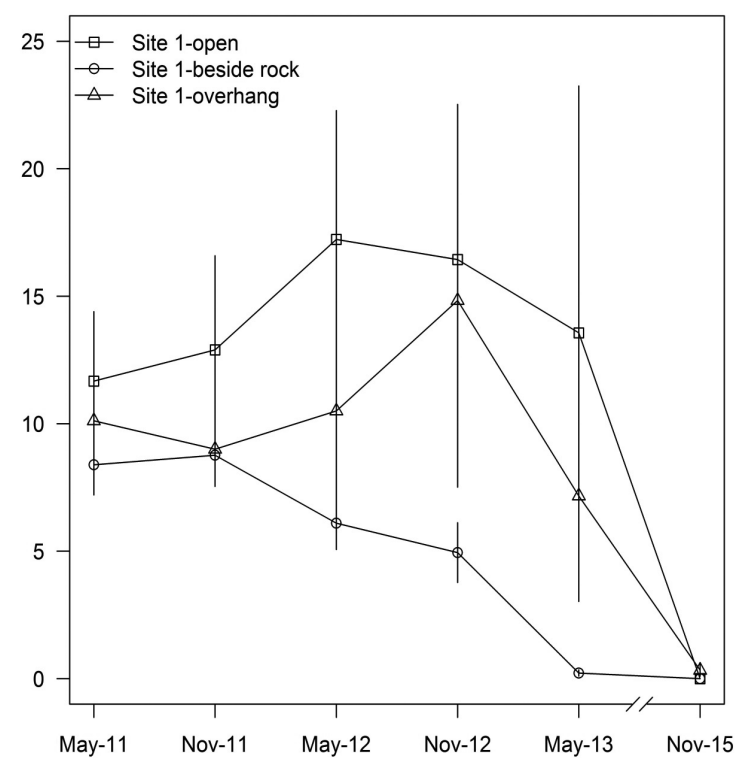

\section{Observation date}

Figure 2: Mean shoot extent $\left(\mathrm{cm}^{2}\right)( \pm 2 \mathrm{SE})$ of (A) C. inopinata and (B) S. laxa from May 2010 to November 2016 within the following microhabitats: open (hollow square, Site 1 only), beside-rock (hollow circle for Site 1, solid circle for Site 2), and rock overhang (hollow triangle for Site 1, solid triangle for Site 2). No measurements were taken between May 2013 and November 2015.

growth between Sites 1 and 2, and between microhabitats, over the entire study period (Figs. 2A \& 3A). In particular, overall growth of $C$. inopinata in Site 1 was higher than at Site 2 across years (Fig. 2A, Table 2). However, observed differences in growth between microhabitats were not statistically significant (Fig. 2A, Table 2). Highest levels of growth alternated between open and beside-rock microhabitats at Site 1 through time (Fig. 2A). This shift of growth between microhabitats was particularly noticeable during the drought, where plants in the open suffered high mortality compared to those beside rocks (Fig. 3A). Overall, $42 \%$ of originally planted C. inopinata individuals survived, but there was no statistical difference in survival between the two sites (Cox: est $=0.39$ $\pm 1.04, \mathrm{z}=0.74, \mathrm{P}=0.46$ ), nor between beside-rock and open microhabitats (Cox: est $=0.47 \pm 1.18, \mathrm{z}=0.80, \mathrm{P}=0.43$ ). However, survival of plants under overhangs was significantly 
A.

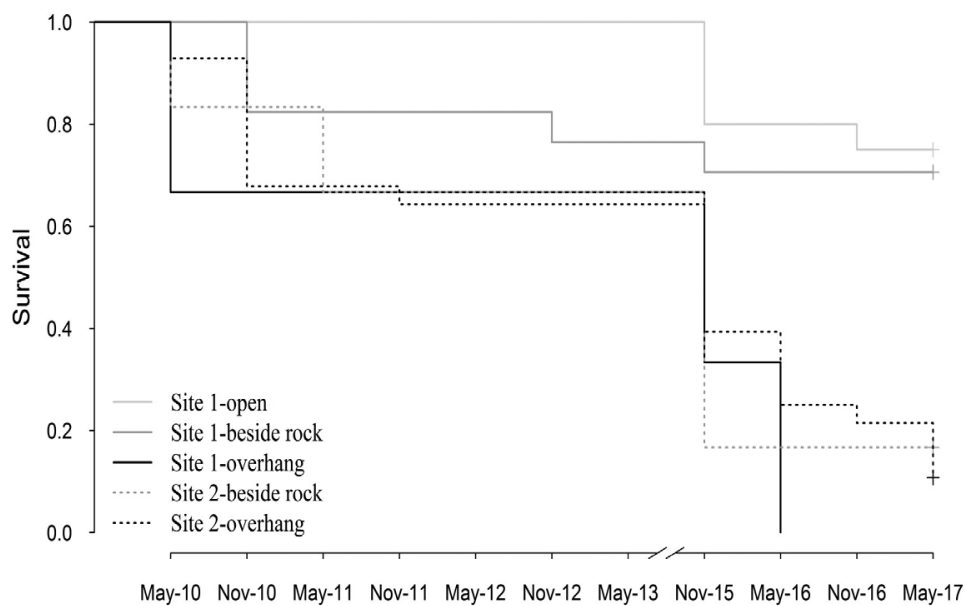

B.

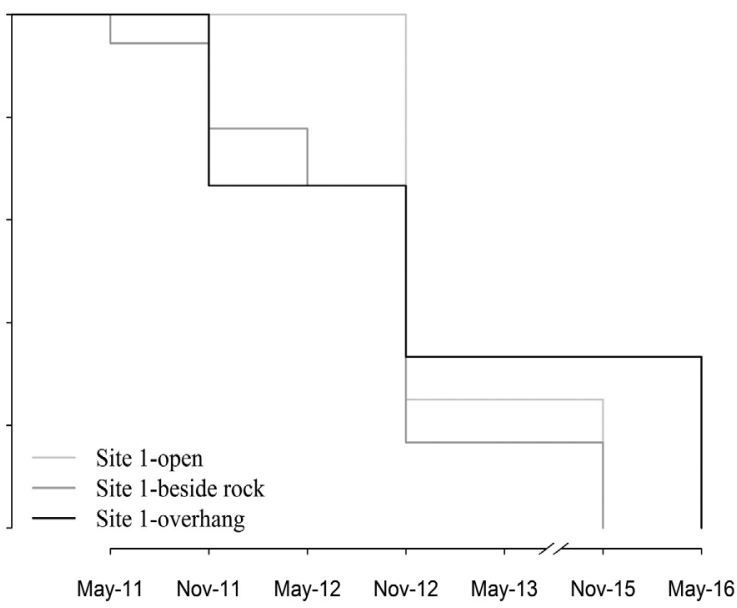

Observation date

Figure 3: Survival of (A) C. inopinata and (B) S. laxa from May 2010 to May 2017 at Site 1 (solid lines) and Site 2 (dashed lines) within the following microhabitats: open (light grey), beside-rock (dark grey) and rock overhang (black). No measurements were taken between May 2013 and November 2015.

Table 2: Coefficient estimates $( \pm 2 \mathrm{SE})$ and associated t-values for the effects of provenance, initial plant size, site, microhabitat, and time on mean shoot extent $\left(\mathrm{cm}^{2}\right)$ of $C$. inopinata and S. laxa translocated to Ōrokonui Ecosanctuary. Significant effect sizes are presented in bold.

Shoot extent of Carex inopinata

\begin{tabular}{|c|c|c|}
\hline Variable & Estimate $( \pm 2 \mathrm{SE})$ & t-value \\
\hline Intercept & $5.53(0.78)$ & 14.01 \\
\hline Provenance (Alexandra, ref. $=$ Rock \& Pillar Range) & $0.82(0.84)$ & 1.93 \\
\hline Initial size (small, ref.= big) & $-2.72(0.82)$ & -6.61 \\
\hline Beside-rock (ref. $=$ open $)$ & $-0.40(1.04)$ & -0.77 \\
\hline Rock overhang (ref. = open) & $-1.15(1.68)$ & -1.37 \\
\hline Site $(2$, ref. $=1)$ & $0.05(1.48)$ & 0.06 \\
\hline Time & $-0.03(0.08)$ & -0.80 \\
\hline Beside-rock $*$ time (ref. $=$ open $)$ & $0.07(0.14)$ & 1.08 \\
\hline Rock overhang $*$ time $($ ref. $=$ open $)$ & $0.04(0.26)$ & 0.32 \\
\hline Site $*$ time $(2$, ref. $=1)$ & $-0.23(0.22)$ & -2.01 \\
\hline \multicolumn{3}{|l|}{ Shoot extent of Simplicia laxa } \\
\hline Variable & Estimate $( \pm 2 \mathrm{SE})$ & t-value \\
\hline Intercept & $3.13(1.02)$ & 6.18 \\
\hline Provenance $(\mathrm{B}$, ref. $=\mathrm{A})$ & $-0.58(1.44)$ & -0.80 \\
\hline Provenance $(\mathrm{C}$, ref. $=\mathrm{A})$ & $0.35(1.48)$ & 0.47 \\
\hline Provenance $(\mathrm{D}$, ref. $=\mathrm{A})$ & $-0.54(1.42)$ & -0.76 \\
\hline Provenance $(\mathrm{E}$, ref. $=\mathrm{A})$ & $-0.11(1.2)$ & -0.19 \\
\hline Provenance $(\mathrm{F}$, ref. $=\mathrm{A})$ & $-0.25(1.46)$ & -0.34 \\
\hline Provenance $(\mathrm{G}$, ref. $=\mathrm{A})$ & $-0.08(1.3)$ & -0.12 \\
\hline Provenance $(\mathrm{H}$, ref. $=\mathrm{A})$ & $0.47(1.42)$ & 0.67 \\
\hline Provenance (seed, ref. $=$ A) & $0.25(1.68)$ & 0.29 \\
\hline Provenance (unknown, ref. = A) & $1.14(1.3)$ & 1.74 \\
\hline Beside-rock (ref. = open) & $-0.96(0.82)$ & -2.35 \\
\hline Rock overhang (ref. = open) & $-0.43(1.02)$ & -0.85 \\
\hline Time & $-0.52(0.06)$ & -15.86 \\
\hline
\end{tabular}


lower than plants in the open (Cox: est $=1.71 \pm 1.40, \mathrm{z}=2.44$, $\mathrm{P}=0.01$ ) (Fig. 3A). Increased vascular plant cover also led to lower survival, although this effect was subtle (Cox: est $=$ $0.02 \pm 0.018, \mathrm{z}=2.07, \mathrm{P}=0.04)$. Provenance had no effect on survival (Cox: est $=-0.63 \pm 0.80, \mathrm{z}=-1.56, \mathrm{P}=0.12$ ), but initially small plants had a significantly higher overall mortality than large plants (Cox: est $=0.97 \pm 0.82, \mathrm{z}=2.33, \mathrm{P}=0.02)$. Flowering mainly occurred at Site 1, with 37 out of 40 plants $(93 \%)$ recorded to have flowered at least once over the study period (mean number of inflorescences $=2.4 \pm 0.71$ [2 SE], range $=0-66)$. In contrast, only 19 out of $34(56 \%)$ plants flowered at Site $2($ mean $=0.23 \pm 0.12$ [2 SE], range $=0-8)$. There was a significant overall decline in flowering at both sites across years (GLMM: est $=-0.43 \pm 0.10, \mathrm{t}=-7.92, \mathrm{P}<$ 0.001 ), particularly at Site 2 (GLMM: est $=-0.60 \pm 0.60, \mathrm{t}=$ $-2.01, \mathrm{P}=0.04)$. The number of inflorescences produced did not differ between microhabitats over time (GLMM: besiderock, est $=0.03 \pm 0.18, \mathrm{t}=0.39, \mathrm{P}=069$; overhangs, est $=$ $-0.06 \pm 0.52, t=-0.25, P=0.80)$. No recruitment occurred during the study period.

\section{Simplicia laxa}

Unlike $C$. inopinata, there was no decrease in average shoot extent of $S$. laxa post-translocation. Instead, growth steadily increased for plants in two of the microhabitats (beside-rock and rock overhang), but rapidly declined due to high mortality (Figs. 2B \& 3B). Hence, there was a significant decrease in overall growth across years (Fig. 2B, Table 2). Growth of $S$. laxa was also significantly lower in beside-rock microhabitats than in the open (Fig. 2B, Table 2), but differences in growth of plants under rock overhangs and in the open were not statistically significant (Table 2). Simplicia laxa eventually suffered $100 \%$ mortality, either during or shortly after the drought in 2015 (Fig. 3B), thus there were no differences in survival for plants in rock microhabitats compared to those in the open (Cox: beside-rock, est $=0.23 \pm 0.90, \mathrm{z}=0.52, \mathrm{P}$ $=0.61$; overhang, est $=-0.24 \pm 1.28, \mathrm{z}=-0.38, \mathrm{P}=0.71)$, nor between provenances (data not shown).

\section{Discussion}

Identifying habitat requirements for relict populations of threatened taxa is of high conservation importance (Osborne $\&$ Seddon 2012). We investigated how various microhabitats influenced the growth and survival of two threatened plants transferred to Ōrokonui and report the short-term outcomes of these experimental translocations.

As predicted, C. inopinata growth, flowering, and survival were highest in the moderately shaded site, and mostly for plants beside rocks and in the open. Highly-shaded sites and microhabitats such as rock overhangs are thus relict refuges for $C$. inopinata. The apparent preference by $C$. inopinata for moderately shaded, not fully shaded, habitats supports earlier research by Morgan and Norton (1992) who found that optimal growth of $C$. inopinata occurred in moderate shade (22-33\% ambient sunlight). Moderate shade is necessary to prevent the growth of potentially competing plants, especially weeds (Ogle 2010). Despite being more sensitive to extreme microclimatic conditions, plant survival was overall highest in open microhabitats, which indicates that this species requires disturbed or partially shaded habitats that mitigate the establishment of other plants. Indeed, increasing levels of ground cover of other, competing plants led to lower survival of C. inopinata.

Although growth was highest in beside-rock and open microhabitats, neither microhabitat can be regarded as having higher habitat quality than the other, given that growth was highest in both microhabitats over time, depending on the microclimatic conditions. Habitat is often considered as a fixed state, in that conservation management tends to focus on characterising habitat associations spatially but not temporally (Van Horne \& Wiens 2015). This approach has led to the inaccurate perception that by conserving what is believed to be the 'highest quality' microhabitat (assessed spatially), then the target species shall persist (Van Horne $\&$ Wiens 2015). For instance, growth of $C$. inopinata was highest in open microhabitats in November 2015, thus one might expect that establishing plants in these areas would optimise their survival. However, when temporal variation is taken into account, it is clear that open microhabitat is not the only habitat requirement to ensure continued growth and survival, as plants established beside rocks did not suffer as high mortality. Hence, growth of plants beside rocks were higher than those in open microhabitats the following year. Therefore, establishing target plants in different microhabitats is essential for increasing the probability of creating a selfsustaining population in the long-term. Thus, although overall survival of $C$. inopinata was lower for plants beside rocks and under rock overhangs than those in the open at Site 1, there is a balance between growth and survival within these microhabitats. Rock overhang microhabitats were clearly not favourable for growth, but were less sensitive to stochastic events such as drought. Narrower ranges of relative humidity and temperature in rock overhangs versus open and besiderock microhabitats, especially at low elevation, attest to such protection. Indeed, shelter provided by rock outcrops within natural habitat has enabled naturally-occurring $C$. inopinata to persist, whereas other more exposed populations presumably suffered extirpation from events such as increased aridity during glaciations, the spread of forest in interglacial periods, fire (natural and human-induced), and grazing by introduced mammals (e.g. rabbits, deer, sheep, etc.; Wood 2007). In many cases, it is fortuitous that refugial populations have persisted at all, given that growth is extremely limited and, from what we observed, the survival of small plants is poor overall. Refugial populations may not have the opportunity to re-colonise wider areas to build up population capacity; hence, as they only exist in small areas, there is confusion surrounding what actually are the species' habitat requirements (Jones 2004). Even at Ōrokonui, the long-term viability of the translocated $C$. inopinata population remains uncertain given that recruitment of seedlings has not been observed. It is also concerning to note that flowering has decreased over the years. Further monitoring of the translocated $C$. inopinata population is necessary to determine whether this population does eventually become self-sustaining through recruitment of seedlings. At this stage, we can only conclude that the translocation of $C$. inopinata to Ōrokonui has been a success in the short-term.

In contrast, the translocation of $S$. laxa was unsuccessful. All plants died after several years, which may indicate that habitat for this species is absent at Örokonui. We did not measure soil chemistry or physical properties, but possibly the soil at Site 1 was not sufficiently base-rich for $S$. laxa persistence. For example, Ogle (2010), who rediscovered Simplicia spp. in North Island alluvial native forest remnants, 
highlighted that well-drained/highly fertile substrates, partial shade, sparse ground cover, and light livestock grazing were all habitat requirements. Furthermore, populations of the closely related Simpliciafelix in the Wairarapa (southern North Island) thrive only in places subjected to light grazing by sheep and cattle under sparse canopy cover, and are absent or scarce in adjacent fenced forests that exclude them (de Lange et al. 2014). It seems that $S$. laxa is similar to $C$. inopinata by requiring some level of disturbance or environmental stress to reduce competition from other plants. While grazing apparently enhances populations of these species in the short-term, the long-term effects are unknown. For example, long-term grazing may cause recruitment failure of canopy trees to replace those that die, in turn admitting more light that may benefit competitors (de Lange et al. 2014); long-term monitoring of populations in grazed sites is needed to evaluate their persistence and regeneration. Another possible reason for the translocation failure is that as the founder population was sourced from a single geographical location (Macraes Flat), the recipient site at Ōrokonui was a poor match for this provenance's ecotype (i.e. locally adapted traits). Therefore, sourcing from multiple natural, but geographically isolated, populations may increase the chance of matching adaptations of the source population to the environmental conditions at the translocation site. Provenance had no apparent effect for the survival and growth of $C$. inopinata, and for the survival of $S$. laxa, but while this nil-effect may hold true for $C$. inopinata, limited data for $S$. laxa would suggest that this lack of an effect is an artefact of low statistical power. However, while we cannot confirm whether an absence of habitat or an inappropriately sourced ecotype was responsible for the translocation failure of $S$. laxa, drought-related mortality certainly contributed to their failure to establish.

Our study, while not yet achieving biological success for either species, was a successful project. With respect to $C$. inopinata, we have demonstrated that rock overhangs beneath a light forest canopy are not favourable for survival. The forest canopy plays the same role as rock overhangs in open country, in providing partial shade that reduces the extent of competition from other ground cover plants, but forest cover in addition to rock overhangs results in too much shade. We also showed that the competitive effect of other ground cover plants is important even beneath a forest canopy, thus translocation sites with persistent open ground are required. For S. laxa, we identified constraints during the propagation phase, when it proved difficult to propagate a large number of experimental units. We then demonstrated that to succeed with a $S$. laxa translocation, factors additional to partial shading and freedom from competition with other ground cover plants are required, most likely related to soil chemistry. These findings should inform future translocations of these species.

\section{Acknowledgements}

We thank E. Urlacher for helping with the survival analyses. We also thank David Trevathan and Melissa Hutchison who assisted with the initial establishment and measurements of C. inopinata, respectively. We appreciate John Barkla and Mike Thorsen (Department of Conservation) for providing the original plants that were propagated for the experiment. Thanks to Ōrokonui Ecosanctuary for the provision of and access to study sites. Lastly, we thank the editors Peter Bellingham and George Perry, plus Hannah Buckley, Sarah Dalrymple and one anonymous reviewer for constructive comments on earlier versions of this manuscript.

\section{References}

Armstrong DP, Seddon PJ 2008. Directions in reintroduction biology. Trends in Ecology and Evolution 23: 20-25.

Bates D, Maechler M, Bolker B, WalkerS 2014.http://CRAN.Rproject.org/package $=$ lme4 (accessed November 2015).

de Lange PJ, Rolfe JR, Champion PD, Courtney SP, Heenan PB, Barkla JW, Cameron EK, Norton DA, Hitchmough RA 2013. Conservation status of New Zealand indigenous vascular plants, 2012. New Zealand Threat Classification Series 3. Wellington, New Zealand, Department of Conservation. $74 \mathrm{p}$.

de Lange PJ, Rolfe JR, Silbery T 2014. Seen but unseenrediscovering Simplicia laxa in the southern North Island. New Zealand Plant Conservation Network Newsletter (Trilepidea) 124: 5-9.

de Lange PJ, Smissen RD, Rolfe JR, Ogle CC 2016. Systematics of Simplicia Kirk (Poaceae, Agrostidinae) - an endemic, threatened New Zealand grass genus. PhytoKeys 75: 119-144.

Dopson SR, de Lange PJ, Ogle CC, Rance BD, Courtney SP, Molloy J 1999. The conservation requirements of New Zealand's nationally threatened vascular plants. Threatened Species Occasional Publication No. 13. Wellington, New Zealand, Department of Conservation. 22 p.

Easton L 2015. Transparency in conservation projects: a case study of Coprosma wallii. Botanical Society of Otago Newsletter 76: 11-12.

Fournier DA, Skaug HJ, Ancheta J, Ianelli J, Magnusson A, Maunder M, Nielsen A, Sibert J 2012. AD model builder: using automatic differentiation for statistical inference of highly parameterized complex nonlinear models. Optimization Methods \& Software 27: 233-249.

Godefroid S, Piazza C, Rossi G, Buord S, Stevens AD, Aguraiuja R, Cowell C, Weekley CW, Vogg G, Iriondo JM, Johnson I, Dixon B, Gordon D, Magnanon S, Valentin B, Bjureke K, Koopman R, Vicens M, Virevaire M, Vanderborght T 2011. How successful are plant species reintroductions? Biological Conservation 144: 672-682.

Jones C 2004. Recovery plan for threatened grassy plants of dry fertile sites, 2003-13. Threatened Species Recovery Plan 52. Wellington, New Zealand, Department of Conservation. $28 \mathrm{p}$.

Jusaitis M 2005. Translocation trials confirm specific factors affecting the establishment of three endangered plant species. Ecological Management \& Restoration 6: 61-67.

Kirk T 1897. On a new genus of Gramineae. Transactions of the New Zealand Institute 29: 497.

Mathewson HA, Morrison ML 2015. The misunderstanding of habitat. In: Morrison ML, Mathewson HA eds. Wildlife habitat conservation: concepts, challenges, and solutions. USA, Johns Hopkins University Press \& The Wildlife Society. Pp. 3-8.

Molloy BPJ 1991. Notes on the rare sedge, Carex inopinata, with particular reference to the Kowhai Point Recreation Reserve, Marlborough Land District. Unpublished report. New Zealand, DSIR Land Resources No. 735. 10 p.

Monks L 2008. Experimental approaches in threatened plant translocations: how failures can still lead to success. Australasian Plant Conservation 17: 8-10. 
Morgan MD, Norton DA 1992. Growth response to light of Carex inopinata Cook, an endangered New Zealand sedge. New Zealand Journal of Botany 30: 429-433.

NIWA 2017. www.niwa.co.nz (accessed November 2017).

Ogle C 2010. Rediscovery of a rare species of grass in the genus Simplicia in the North Island. Wellington Botanical Society Bulletin 52: 38-46.

Osborne PE, Seddon PJ 2012. Selecting suitable habitats for reintroductions. In: Ewen JG, Armstrong DP, Parker KA, Seddon PJ eds. Reintroduction biology: integrating science and management. UK, Blackwell Publishing. Pp. 73-104.

R Core Team 2013. R: a language and environment for statistical computing. $R$ foundation for statistical computing. Vienna, Austria. www.R-project.org (accessed September 2015).

Skaug H, Fournier D, Bolker B, Magnusson A, Nielsen A 2014. Generalized linear mixed models using AD Model Builder. http://glmmadmb.r-forge.r-project.org (accessed September 2015).

Editorial board member: Peter Bellingham

Received 17 July 2017; accepted 5 December 2017
Smissen RD, de Lange PJ, Thorsen MJ, Ogle CC 2011. Species delimitation and genetic variation in the rare New Zealand endemic grass genus Simplicia. New Zealand Journal of Botany 49: 187-199.

Therneau TM, Grambsch PM 2000. Modeling survival data: extending the Cox Model. USA, Springer. $350 \mathrm{p}$.

Van Horne B, Wiens JA2015. Managing habitats in a changing world. In: Morrison ML, Mathewson HA eds. Wildlife habitat conservation: concepts, challenges, and solutions. USA, Johns Hopkins University Press \& The Wildlife Society. Pp. 34-43.

Wood JR 2007. Pre-settlement paleoecology of Central Otago's semi-arid lowlands, with emphasis on the pre-settlement role of avian herbivory in South Island dryland ecosystems, New Zealand. Unpublished PhD thesis, University of Otago, Dunedin, New Zealand. 432 p. 